\title{
Energy-loss mechanism of boilers system in large-scale coal- fired power plants and the corresponding energy-saving approaches
}

\author{
Weiliang WANG*, Yuzhao WANG**, Xuan YAO*, Pan ZHANG*, Junfu LYU* and Weidou NI* \\ * State Key Laboratory of clean and efficient coal-fired power generation and pollution control, Key Laboratory for Thermal Science and \\ Power Engineering of Ministry of Education, Department of Energy and Power Engineering, Tsinghua University, Beijing 100084, China \\ Email:wang_wl@tsinghua.edu.cn \\ ${ }^{* *}$ Chengde Petroleum College, Chengde 067000, China
}

Received: 26 February 2019; Revised: 18 April 2019; Accepted: 10 June 2019

\begin{abstract}
To evaluate the energy efficiency of the energy conversion and transfer, and the dig energy-saving potential during coal-fired power generation, the energy-loss mechanism was determined through a comparative analysis of thermal and exergy equilibria. Energy loss is first identified as exergy destruction, which is then gradually collected and finally discharged in the form of waste heat through terminals such as a condenser. Furthermore, the exergy-destruction distribution represents the theoretical energy-saving potential, which occurs mainly in the boiler. Accordingly, an in-depth study was conducted on the technical approaches to reduce the combustion- and heat transfer-induced exergy-destruction and other exergy-destruction in the boiler. These technical approaches include elevating hot-air temperature, oxy combustion, reducing excess air coefficient, and increasing the main steam/reheated steam parameters. Results show that technical solutions of elevating the hot-air temperature, increasing the air oxygen content, elevating the main steam/reheated steam temperature, and increasing the main steam pressure can reduce the net coal-consumption rate of a coal-fired power unit by 6-9, 6-10, 11, and 5$12 \mathrm{~g} / \mathrm{kW} \cdot \mathrm{h}$, respectively. These conclusions indicate the direction of the development of energy-saving technologies for coal-fired power generation.
\end{abstract}

Keywords : Air preheating, Coal-fired, Energy-saving, Exergy, High parameters, Oxy combustion

\section{Introduction}

Coal is the primary energy source in the world. The current coal consumption accounts for about 30\% (BP Company, 2018) of the total energy consumption worldwide and contributes to nearly $40 \%$ of the total power generation (IEA, 2018). However, the energy consumption ratio of coal and its contribution proportion to the national power generation reach 60\% (National Bureau of Statistics of China, 2017) and 70\% (China Electricity Council, 2018), respectively, in China. Coal-fired boiler is among the three major equipment in the coal-fired power generation system; the boiler facilitates the high-efficiency coal combustion and transfer of the released energy to steam/water to supply the steam with stipulated quantity and quality to the turbine (Feng, et al., 2003). Two types of large-scale coal-fired boilers (300 MW and above capacity) currently exist: pulverized coal-fired and circulating fluidized bed boiler (Feng, et al., 2003). The energy conversion efficiency of a boiler mainly influences the system efficiency of a coal-fired power plant.

Based on the first law of thermodynamics, the heat loss during coal-fired power generation mainly lies during the condensation of exhaust steam, usually accounting for over $50 \%$ of the fuel energy content (Tillman, 2018). This part of heat loss is necessary for establishing a Rankine cycle. The thermal efficiency of a large scale coal-fired boiler is generally above $90 \%$ and that of a state-of-the-art coal-fired boiler may reach over 95\% (China Electricity Council, 2018), which 
limits the efficiency improvement margin of a boiler.

An exergy concept, which describes the maximum useful work of a system, was systematically introduced by Zhu as early as the 1880s (Zhu, 1983). Different exergy types such as physical, chemical, and electric power exergy (Xiang, 1985a) and their related computational methods (Xiang, 1985b) were then discussed by Xiang in details. Accordingly, an exergy equilibrium computation of a $140 \mathrm{t} / \mathrm{h}$ power station boiler was conducted by $\mathrm{Li}(\mathrm{Li}, 1986)$, which revealed the energy loss process during energy conversion. Nevertheless, the complicated computation process of exergy equilibrium is hardly conducted within the industrial circles, which limits its popularization and application to academic studies.

With increasing attention paid to energy-saving technologies within the electric power industry, studies on the exergy efficiency of 410, 670 (210 MW), and $1900 \mathrm{t} / \mathrm{h}$ (600 MW) boilers have been carried out by Chen (Chen, 2004), Sengupta, et al. (Sengupta, et al., 2007)., and Wang et al. (Wang, et al., 2016), respectively. The investigation of exergy destructions within the whole plant with 600 and $660 \mathrm{MW}$ supercritical coal-fired power generation units were also conducted by Liu and Duan (Liu, et al., 2010) and Yang et al. (Yang, et al., 2013), respectively. The exergy equilibrium method has also been extensively applied to the analysis of energy consumption and economic efficiency of systems, including solar energy combined power generation (Zhu, et al., 2016; Adibhatla, et al., 2017), combined cycle power generation (Nami, et al., 2017), ground source heat pump system(Menberg, et al., 2017), lignite drying power generation (Han, et al., 2017), poly-generation with circulating fluidized bed (Gürtürk, et al., 2016; Tumen Ozdil, et al., 2016), optimization of heat supply network (Semkov, et al., 2014), distributed energy (Compton, et al., 2017), organic Rankine cycle (Darvish, et al., 2015; Zhao, et al., 2017), and $\mathrm{CO}_{2}$-capturing (Jin, et al., 2016).

Based on many studies on exergy equilibrium, in-depth analyses have been carried out to determine the exergy destructions of different systems in coal-fired power generation and related energy conversion processes. Generally, the exergy destruction during coal-fired power generation mainly occurs inside the boiler, and the combustion- and heat transfer-induced exergy destruction mainly account for the boiler exergy destruction (Uysal, et al., 2017). A series of suggestions for reducing exergy destruction are proposed according to the exergy destruction distribution by elevating steam parameters (Liu, 2010), feedwater temperature, and load rate (Si, et al., 2017), lowering backpressure, and changing the method for air preheating ( $\mathrm{Li}$, et al., 2017).

However, the internal relation between exergy destruction and heat loss has not been discussed in previous publications, hence, then energy-destruction mechanisms of coal-fired power generation is still unclear. Besides, questions related to whether exergy destruction can be regarded as energy-saving potential, what kind of energy-saving techniques that should be focused on, and the what amount of energy-saving potential could be achieved based on current technologies, have not been well discussed by the published literatures.

Therefore, to reveal the internal relationship between heat and exergy destructions and discover the energydestruction mechanisms of coal-fired power generation, a comparative analysis of thermal and exergy equilibria was considered for the evaluation of energy efficiency for typical large scale coal-fired power units in this paper. Based on the exergy-destruction distribution, an in-depth discussion was conducted for related energy-saving approaches. Then, the energy-saving potentials of the large-scale coal-fired power generation process were revealed, and the corresponding development direction of energy-saving technologies were proposed.

\section{Evaluation method for exergy in coal-fired boilers}

\subsection{Exergy equilibrium}

In thermodynamics, the exergy of a system is the maximum useful work possible during a process that brings the system into equilibrium with a heat reservoir. Taking the surroundings as the reservoir, exergy is the potential of a system to cause a change as it achieves equilibrium with its surroundings. After the system and surroundings reach equilibrium, the exergy is zero (Xiang, 1985a).

\subsubsection{Chemical exergy}

A fuel under environmental status can react with the oxygen in the air to release chemical energy, resulting in chemical disequilibrium. Chemical exergy refers to the maximum work that can be obtained upon the reaction of fuel with reference substances present in the environment (Xiang, 1985a; Thomson, 1848). Generally, the chemical exergy of 
a solid fuel is approximately the sum of its lower heating value and the latent heat of vaporization of its moisture content under normal temperature and pressure (Zhu, 1983; Li, 1986). According to Eq. (1):

$$
E_{\mathrm{x}, \mathrm{f}, \mathrm{c}}=Q_{\mathrm{net}, \mathrm{ar}}+r \cdot w
$$

where

$E_{\mathrm{x}, \mathrm{f}, \mathrm{c}}$ - chemical exergy, $\mathrm{kJ} / \mathrm{kg}$;

$Q_{\text {net,ar }}$ - lower heating value as received basis, $\mathrm{kJ} / \mathrm{kg}$;

$r$ - latent heat of vaporization, $\mathrm{kJ} / \mathrm{kg}$;

$w$ - water content.

\subsubsection{Exergy of working medium}

Under steady-state conditions, all heat exchange processes inside the thermodynamic system of a coal-fired power generation unit can be regarded as stable open systems. Due to the relatively small differences in the potential and speed of the working medium between the inlet and outlet of thermodynamic systems, the exergy of the working medium is usually calculated according to Eq. (2):

$$
e_{\mathrm{x}, \mathrm{H}}=h-h_{0}-T_{0}\left(s-s_{0}\right)
$$

where

$e_{\mathrm{x}, \mathrm{H}}$ - exergy of $1 \mathrm{~kg}$ (or $1 \mathrm{Nm}^{3}$ ) working medium, $\mathrm{kJ} / \mathrm{kg}$ (or $\mathrm{kJ} / \mathrm{Nm}^{3}$ );

$h$ - enthalpy of $1 \mathrm{~kg}$ (or $1 \mathrm{Nm}^{3}$ ) working medium, $\mathrm{kJ} / \mathrm{kg}$ (or $\mathrm{kJ} / \mathrm{Nm}^{3}$ );

$h_{0}$ - enthalpy of $1 \mathrm{~kg}$ (or $1 \mathrm{Nm}^{3}$ ) working medium under environmental condition, $\mathrm{kJ} / \mathrm{kg}$ (or kJ/Nm${ }^{3}$ );

$\mathrm{s}$ - entropy of $1 \mathrm{~kg}$ (or $\left.1 \mathrm{Nm}^{3}\right)$ working medium, $\mathrm{kJ} /(\mathrm{kg} \cdot \mathrm{K})$ (or $\mathrm{kJ} /\left(\mathrm{Nm}^{3} \cdot \mathrm{K}\right)$;

$s_{0}$ —entropy of $1 \mathrm{~kg}$ (or $1 \mathrm{Nm}^{3}$ ) working medium under environmental condition, $\mathrm{kJ} /(\mathrm{kg} \cdot \mathrm{K})\left(\right.$ or $\left.\mathrm{kJ} /\left(\mathrm{Nm}^{3} \cdot \mathrm{K}\right)^{3}\right)$;

$T_{0}$ — ambient thermodynamic temperature, $\mathrm{K}$.

For an ideal gas, the entropy change per unit volume is calculated according to Eq. (3):

$s-s_{0}=c_{\mathrm{p}, \mathrm{av}} \ln \left(\frac{T}{T_{0}}\right)-R \ln \left(\frac{P}{P_{0}}\right)$

where

$c_{\mathrm{p}, \mathrm{av}}$ - average specific heat at constant gas pressure from $T_{0}$ to $T, \mathrm{~kJ} /\left(\mathrm{Nm}^{3} \cdot \mathrm{K}\right)$;

$T$ - temperature, $\mathrm{K}$;

$P$ - pressure, $\mathrm{kPa}$;

$P_{0}$ — ambient pressure, $\mathrm{kPa}$;

$R$ - gas constant, $R=0.371 \mathrm{~kJ} /\left(\mathrm{Nm}^{3} \cdot \mathrm{K}\right)$.

The following can be obtained by substituting Eq. (3) into Eq. (2):

$e_{\mathrm{x}, \mathrm{H}}=h-h_{0}-T_{0} c_{\mathrm{p}, \mathrm{av}} \ln \left(\frac{T}{T_{0}}\right)+R T_{0} \ln \left(\frac{P}{P_{0}}\right)$

Set

$e_{\mathrm{x}, \mathrm{T}}=h-h_{0}-T_{0} c_{\mathrm{p}, \mathrm{av}} \ln \left(\frac{T}{T_{0}}\right)$

$e_{\mathrm{x}, \mathrm{p}}=R T_{0} \ln \left(\frac{P}{P_{0}}\right)$

The right side of Eq. (5) is related to temperature, which refers to the thermal component of thermomechanical exergy. The right side of Eq. (6) is only related to the pressure, which refers to the mechanical component of thermomechanical exergy. Therefore, the exergy of an ideal gas is equivalent to the sum of the thermal and mechanical components of thermomechanical exergy. In the boiler calculation, both flue gas and air are taken as ideal gases. Hence, Eq. (4), (5), and (6) are applicable to the exergy calculation of flue gas and air.

For solid matter, the entropy change per unit mass is calculated according to Eq. (7): 


$$
s-s_{0}=c_{\mathrm{av}} \ln \left(\frac{T}{T_{0}}\right)
$$

where

$C_{\mathrm{av}}$ - average specific heat from $T_{0}$ to $T, \mathrm{~kJ} /(\mathrm{kg} \cdot \mathrm{K})$;

The exergy of unit solid can be obtained from Eq. (8) by substituting Eq. (7) into Eq. (2):

$e_{\mathrm{x}, \mathrm{H}}=h-h_{0}-T_{0} c_{\mathrm{av}} \ln \left(\frac{T}{T_{0}}\right)$

Eq. (8) is applicable to the calculation of thermomechanical exergy of flying ash, cinder, and fuel.

\subsubsection{Electric power exergy}

As all electric energy can be converted to useful work, electric power exergy value is equal to the heat quantity converted by electric power, and the exergy of $1 \mathrm{~kW} \cdot \mathrm{h}$ of electric power is $3600 \mathrm{~kJ}$.

\subsection{Boiler exergy equilibrium}

Exergy equilibrium calculation is not usually applied to the boiler system. Based on related literature (Wang, 2016; Li, 1986; Liu, 2010; Chen, 2004), the boiler exergy equilibrium was calculated with some modifications. The exergy input of the boiler system includes the chemical exergy of the fuel and electric power exergy of the service power in the boiler system. The chemical exergy of fuel is first converted into thermomechanical exergy of the high-temperature flue gas in a boiler through combustion and then transferred to the working medium through surface heat transfer. The schematic of the substance and exergy-conversion process is shown in Fig. 1. Part of the service power exergy was converted into mechanical exergy in the forms of work and movement, which are then consumed when overcoming frictional resistance, overcoming the flow resistance of the working medium, and crushing. The exergy output of the boiler system mainly refers to the exergy increment generated when heating feedwater and cold-reheated steam into the main and reheated steam, respectively.

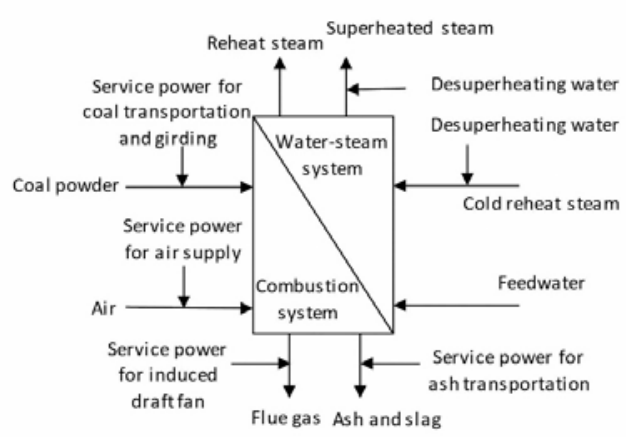

Fig. 1 Boiler substance and energy flow

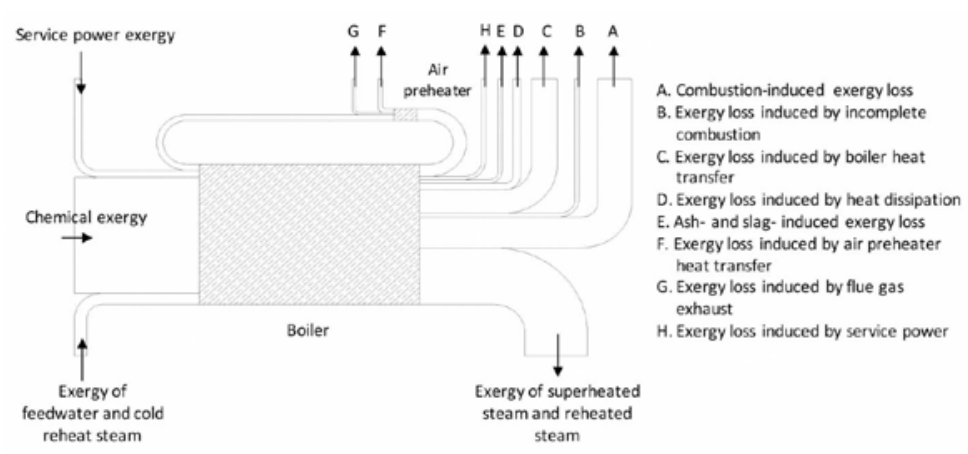

Fig. 2 Boiler exergy flowchart

The exergy destruction in the boiler system mainly includes the exergy destruction induced by combustion, incomplete combustion, boiler heat transfer, boiler heat dissipation, the ash and slag, the air preheater heat transfer, the flue gas exhaust, and the service power (Fig. 2).

The combustion-induced exergy destruction refers to exergy destruction generated during the ideal adiabatic combustion process when the chemical exergy was fully converted into heat exergy. The exergy destruction induced by incomplete combustion refers to the unconverted chemical exergy. The exergy destruction induced by boiler heat transfer results from the heat transfer between the flue gas and the working medium. The exergy destruction induced by air preheater heat transfer is generated from the heat transfer between the air and flue gas inside the air preheater. A part of the service power exergy consumed by coal transportation, coal-grinding, and auxiliary equipment efficiency loss is converted into heat, which can be absorbed by the working medium or dissipated in the environment. The absorbed heat in the working medium is relatively small, which makes its effect on the exergy increment of working medium negligible; this part of service power exergy is recorded as the service power exergy destruction. The other part of the service power 
exergy is converted into the flow exergy of the air or flue gas, which is initially fed into the boiler system and then consumed by the flow processes in boiler flue and heating surface. This part of service power exergy is accounted into the exergy destruction in the flue gas exhaust. The exergy destruction of the boiler system is expressed by Eq. (9):

$$
E_{\mathrm{x}, \mathrm{B}, \mathrm{d}}=E_{\mathrm{x}, \mathrm{d}, \mathrm{fc}}+E_{\mathrm{x}, \mathrm{d}, \mathrm{ic}}+E_{\mathrm{x}, \mathrm{d}, \mathrm{b}, \mathrm{ht}}+E_{\mathrm{x}, \mathrm{d}, \mathrm{ap}, \mathrm{ht}}+E_{\mathrm{x}, \mathrm{d}, \mathrm{fg}}+E_{\mathrm{x}, \mathrm{d}, \mathrm{as}}+E_{\mathrm{x}, \mathrm{d}, \mathrm{he}}+E_{\mathrm{x}, \mathrm{d}, \mathrm{spc}}
$$

where

$E_{\mathrm{x}, \mathrm{d}, \mathrm{fc}}$ - combustion-induced exergy destruction, $\mathrm{kJ} / \mathrm{kg}$;

$E_{\mathrm{x}, \mathrm{d}, \mathrm{ic}}$ - exergy destruction induced by incomplete combustion, $\mathrm{kJ} / \mathrm{kg}$;

$E_{\mathrm{x}, \mathrm{d}, \mathrm{b}, \mathrm{ht}}$ - exergy destruction induced by boiler heat transfer, $\mathrm{kJ} / \mathrm{kg}$;

$E_{\mathrm{x}, \mathrm{d}, \mathrm{ap}, \mathrm{ht}}$ - exergy destruction induced by air pre-heater heat transfer, $\mathrm{kJ} / \mathrm{kg}$;

$E_{\mathrm{x}, \mathrm{d}, \mathrm{fg}}$ - exergy destruction induced by flue gas exhaust, $\mathrm{kJ} / \mathrm{kg}$;

$E_{\mathrm{x}, \mathrm{d}, \mathrm{as}}$ - ash- and slag-induced exergy destruction, $\mathrm{kJ} / \mathrm{kg}$;

$E_{\mathrm{x}, \mathrm{d}, \mathrm{he}}$ - exergy destruction induced by heat dissipation, $\mathrm{kJ} / \mathrm{kg}$;

$E_{\mathrm{x}, \mathrm{d}, \mathrm{spc}}$ - exergy destruction induced by service power, $\mathrm{kJ} / \mathrm{kg}$.

\section{Discussion on energy loss distribution and energy-saving potentials}

\subsection{Energy loss distribution of coal-fired power generation}

To analyze the energy loss distribution of large scale coal-fired power generation process, four typical units, including a $300 \mathrm{MW}$ subcritical unit, a $600 \mathrm{MW}$ supercritical air-cooling unit, a $1000 \mathrm{MW}$ ultra-supercritical unit and a $1000 \mathrm{MW}$ ultra-supercritical secondary reheating unit, were selected as the research objects. Thermal and exergy equilibria calculations were conducted simultaneously on the above units. The main parameters of these units are shown in Table 1, and their heat and exergy-destruction distributions are shown in Tables 2 and 3, respectively.

Table 1 Main parameters of typical coal-fired generator units

\begin{tabular}{l|l|l|l|l|l}
\hline \hline Unit No. & Unit & U1 & U2 & U3 & U4 \\
\hline Capacity level & MW & 300 & 600 & 1000 & 1000 \\
Main steam pressure & MPa & 17.28 & 25.2 & 27.18 & 31.14 \\
Main steam temperature & ${ }^{\circ} \mathrm{C}$ & 541 & 571 & 605 & 605 \\
Reheating times & Times & 1 & 1 & 1 & 2 \\
Ash content of fuel as received basis & $\%$ & 19.77 & 12.61 & 9.1 & 8.8 \\
Volatile components of fuel drying machine & $\%$ & 32.31 & 32.59 & 34.08 & 34.73 \\
Lower heating value of the fuel & $\mathrm{kJ} / \mathrm{kg}$ & 22440 & 19250 & 23470 & 23440 \\
Excess air coefficient of furnace outlet & - & 1.25 & 1.2 & 1.25 & 1.15 \\
Flue gas exhaust temperature & ${ }^{\circ} \mathrm{C}$ & 125.6 & 124 & 123 & 117 \\
\hline
\end{tabular}

Table 2. Heat loss distribution of different typical generator units

\begin{tabular}{l|l|l|l|l}
\hline \hline Unit No. & $\mathrm{U} 1$ & $\mathrm{U} 2$ & $\mathrm{U} 3$ & $\mathrm{U} 4$ \\
\hline Heat loss of incomplete combustion, \% & 1.07 & 1.03 & 0.82 & 0.48 \\
Heat loss through ash and heat dissipation, \% & 0.28 & 0.26 & 0.24 & 0.22 \\
Heat loss in flue gas exhaust, \% & 5.87 & 5.80 & 5.46 & 5.11 \\
Boiler service power heat loss, \% & 1.47 & 1.06 & 0.68 & 1.18 \\
Pipeline loss, \% & 0.32 & 0.62 & 0.46 & 0.73 \\
Heat loss of the heat regenerative system, \% & 0.39 & 0.04 & 0.12 & 0.03 \\
Turbine service power heat loss, \% & 0.34 & 0.76 & 0.21 & 0.35 \\
Cold end heat loss, \% & 49.67 & 50.65 & 47.02 & 45.72 \\
Power generation heat loss, \% & 0.40 & 0.32 & 0.24 & 0.22 \\
Power supply efficiency, \% & 40.19 & 39.45 & 44.76 & 45.95 \\
\hline
\end{tabular}

As the fuel exergy is calculated by adding the lower heating value and latent heat of vaporization of the fuel, the 
total system input quantities of thermal and exergy equilibrium are slightly different. Consequently, the power supply efficiencies calculated from the thermal and exergy equilibria are slightly different (difference rate is about $0.2 \%$ ) (Tables 2 and 3). This slight difference does not affect their overall consistency. However, the calculated loss distribution based on thermal and exergy equilibria have a significant difference. Taking the $300 \mathrm{MW}$ unit as an example, the cold-side heat loss generated by the condenser through thermal equilibrium analysis accounts for about 50\%, which is the main heat loss of the coal-fired power station, whereas the accumulated boiler heat loss only accounts for $\sim 9 \%$. According to the exergy equilibrium analysis, the sum of the exergy destructions induced from the combustion and boiler heat transfer reaches $47 \%$, which is the main exergy destruction of the coal-fired power station. On the contrary, the cold-side exergy destruction of the condenser only accounts for $1.3 \%$.

Table 3. Exergy-destruction distribution of different typical generator units

\begin{tabular}{l|l|l|l|l}
\hline \hline Unit No. & $\mathrm{U} 1$ & $\mathrm{U} 2$ & $\mathrm{U} 3$ & $\mathrm{U} 4$ \\
\hline Combustion induced exergy destruction, \% & 26.82 & 26.80 & 26.30 & 25.98 \\
Exergy destruction of incomplete combustion, \% & 0.80 & 0.79 & 0.55 & 0.16 \\
Exergy destruction in boiler heat transfer, \% & 19.70 & 17.76 & 17.67 & 16.51 \\
Exergy destruction through ash and heat dissipation, \% & 0.05 & 0.04 & 0.02 & 0.02 \\
Exergy destruction in the heat transfer of air pre-heater, \% & 1.11 & 1.29 & 1.01 & 1.12 \\
Exergy destruction in the flue gas exhaust, \% & 0.79 & 0.77 & 0.73 & 0.63 \\
Boiler service power exergy destruction, \% & 1.97 & 1.54 & 0.99 & 1.67 \\
Pipeline exergy destruction, \% & 0.65 & 0.80 & 0.77 & 0.84 \\
Turbine inner efficiency exergy destruction, \% & 3.75 & 3.37 & 3.46 & 3.54 \\
Exergy destruction of the heat regenerative system, \% & 1.16 & 1.06 & 1.18 & 1.45 \\
Turbine service power exergy destruction, \% & 0.43 & 2.26 & 0.28 & 0.40 \\
Cold end exergy destruction, \% & 1.31 & 4.54 & 1.24 & 0.97 \\
Power generation exergy destruction, \% & 0.18 & 0.48 & 0.12 & 0.18 \\
Power supply efficiency, \% & 40.39 & 39.62 & 45.00 & 46.18 \\
\hline
\end{tabular}

Considering the energy conversion and transfer direction in the coal-fired power generation process, a comprehensive comparative analysis is carried out between the distributions of heat and exergy destructions. If the exergy destructions are gradually gathered along the energy conversion and transfer direction, their accumulated values at terminals such as condenser are consistent with the corresponding heat loss in quantity. Thus, the exergy destruction reflects the concrete energy loss process during coal-fired power generation, whereas heat loss reflects the final rejection port of energy loss to leave the thermodynamic system. Therefore, the analysis of energy-saving potentials during coalfired power generation should be conducted according to the analysis of exergy-destruction distribution.

\subsection{Energy-saving potential of the boiler system}

Based on the exergy-destruction distribution in Table 3 during coal-fired power generation, the combustion-induced exergy destruction is at maximum, accounting for $\sim 27 \%$ of the total system exergy input, followed by the exergy destruction induced by boiler heat transfer (17\%-21\%), with a total of $43 \%-48 \%$, accounting for about $80 \%$ of total exergy destruction. These are the basic factors influencing the power generation efficiency. Therefore, the reduction of exergy destruction induced by combustion and heat transfer was emphasized to determine the energy-saving potentials. Related energy-saving technologies for coal-fired boiler were discussed accordingly.

\subsubsection{Approaches on the reduction of combustion-induced exergy destruction}

Combustion-induced exergy destruction accounts for the highest exergy destructions from power generation. It can only be reduced by elevating the adiabatic combustion temperature of the boiler. Generally, the adiabatic combustion temperature can be elevated through several methods, such as elevating the input temperature of the pulverized coal and hot air, increasing the oxygen concentration, and reducing the excess air coefficient. The elevation of pulverized coal 
temperature is hardly achieved under the present technical conditions due to restricting factors such as safety and heating method. Then, the effects of elevating the hot-air temperature, increasing the oxygen concentration (oxy combustion), and reducing the excess air coefficient of the boiler on reducing the combustion-induced exergy destruction were investigated. The most dominant typical $1000 \mathrm{MW}$ ultra-supercritical coal-fired power unit is adopted to proceed with the investigation of the mentioned approaches.

\section{(1) Elevating the hot-air temperature by staged air preheating}

As proposed in previous study, staged air preheating technology that adopts a crossed arrangement of the air preheater and economizer can elevate the hot-air temperature by around 40-60 ${ }^{\circ} \mathrm{C}$ (Wang, 2015). By adopting exergy equilibrium method, the exergy destructions of related processes in thermodynamic system are calculated. Figure 3 shows the changes in adiabatic combustion temperature $\left(T_{\mathrm{ad}, \mathrm{f}}\right)$, the combustion induced exergy destruction, the boiler heat transfer induced exergy destruction, the boiler flue gas exhaust temperature $\left(T_{-} \mathrm{fg}\right)$, the flue gas exhaust induced exergy destruction, the air preheater heat transfer induced exergy destruction and the total exergy destruction of the boiler system when hot-air temperature is elevated by 20,40 and $60^{\circ} \mathrm{C}$ respectively.

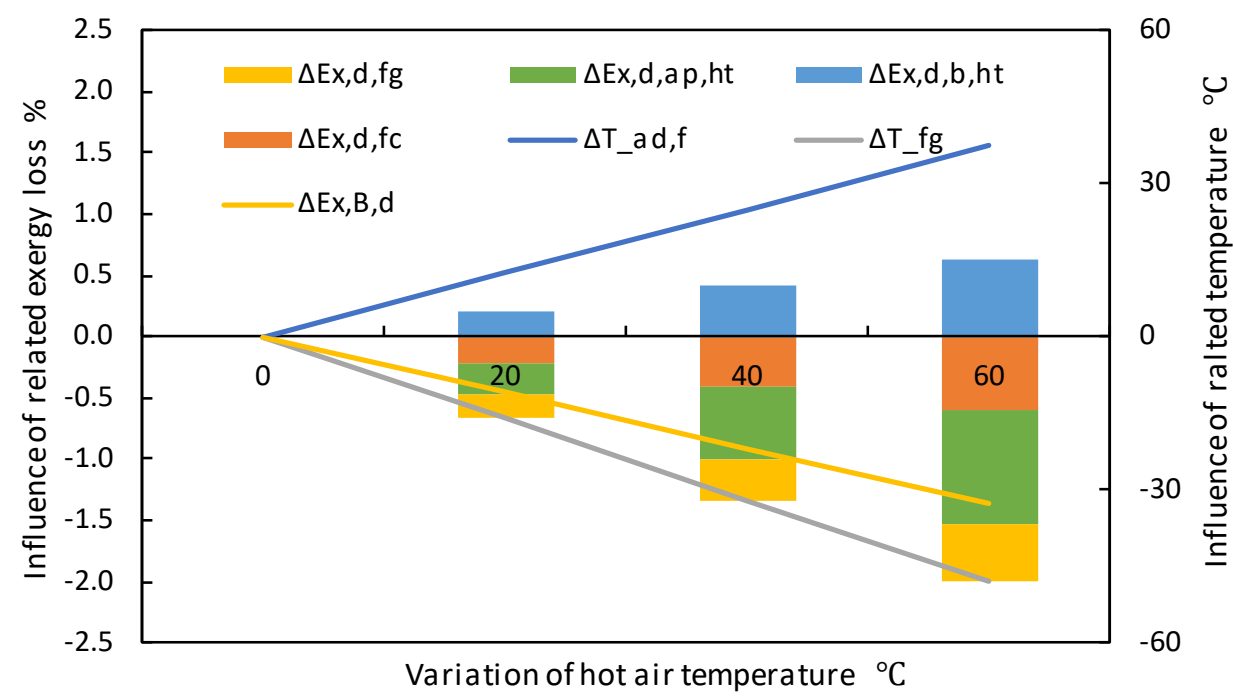

Fig. 3 Influence of elevating the hot-air temperature

As the hot-air temperature is increased, adiabatic combustion temperature is elevated, as the result, the combustioninduced exergy destruction is reduced. It can be seen in Figure 3 that the increase in hot-air temperature results in a nearly linear growth of adiabatic combustion temperature with a relative growth rate of $\sim 60 \%$ and a nearly linear decline in combustion-induced exergy destruction. However, as the adiabatic combustion temperature is elevated, the heat transfer temperature difference between the flue gas and steam/water increases, and so does the exergy destruction induced by boiler heat transfer. As shown in Figure 3, the exergy destruction induced by boiler heat transfer grows along with the increasing of hot-air temperature, with a rate very close to the decline rate of the combustion-induced exergy destruction. As the energy used to elevate the hot-air temperature is originated from the flue gas, thus, increasing the hot-air temperature will definitely lower the flue gas exhaust temperature. As the specific heat capacity of flue gas is higher than the air, it can be shown by Figure 3 that the flue gas exhaust temperature declines linearly with a reverse relative variation rate of around $80 \%$ of that of the hot-air temperature. As the decline of flue gas temperature, and the average heat transfer temperature difference between the flue gas and air decreases, thus, the exergy destructions induced by air preheater heat transfer and the flue gas exhaust decline.

At the same time, Consequently, the exergy destructions induced by the flue gas exhaust and air preheater heat transfer will be decreased

The final effect of elevating the hot-air temperature is embodied by the reduction of the exergy destruction induced by air preheater heat transfer and boiler flue gas exhaust. When the hot-air temperature is elevated by $40-60{ }^{\circ} \mathrm{C}$, the total 
boiler exergy destruction can be reduced by $\sim 0.91 \%-1.37 \%$. As a result, the net coal-consumption rate of a coal-fired power unit can be reduced by $\sim 6^{-9} \mathrm{~g} / \mathrm{kW} \cdot \mathrm{h}$ (on the basis of $45 \%$ power supply efficiency, similarly hereinafter).

\section{(2) Oxy combustion}

By adopting the air separation technology, the oxygen content in the air can be elevated. As the useless gas, like $\mathrm{N}_{2}$, is reduced from the air, the overall heat capacity of flue gas is reduced correspondently. As a result, the adiabatic combustion temperature would be elevated and the combustion-induced loss would be reduced. Figure 4 shows the changes in boiler adiabatic combustion temperature and the exergy destruction induced by combustion, boiler heat transfer, air preheater heat transfer, the flue gas exhaust, and the total boiler when the oxygen concentration in the air is elevated to $40 \%, 60 \%, 80 \%$, and $100 \%$.

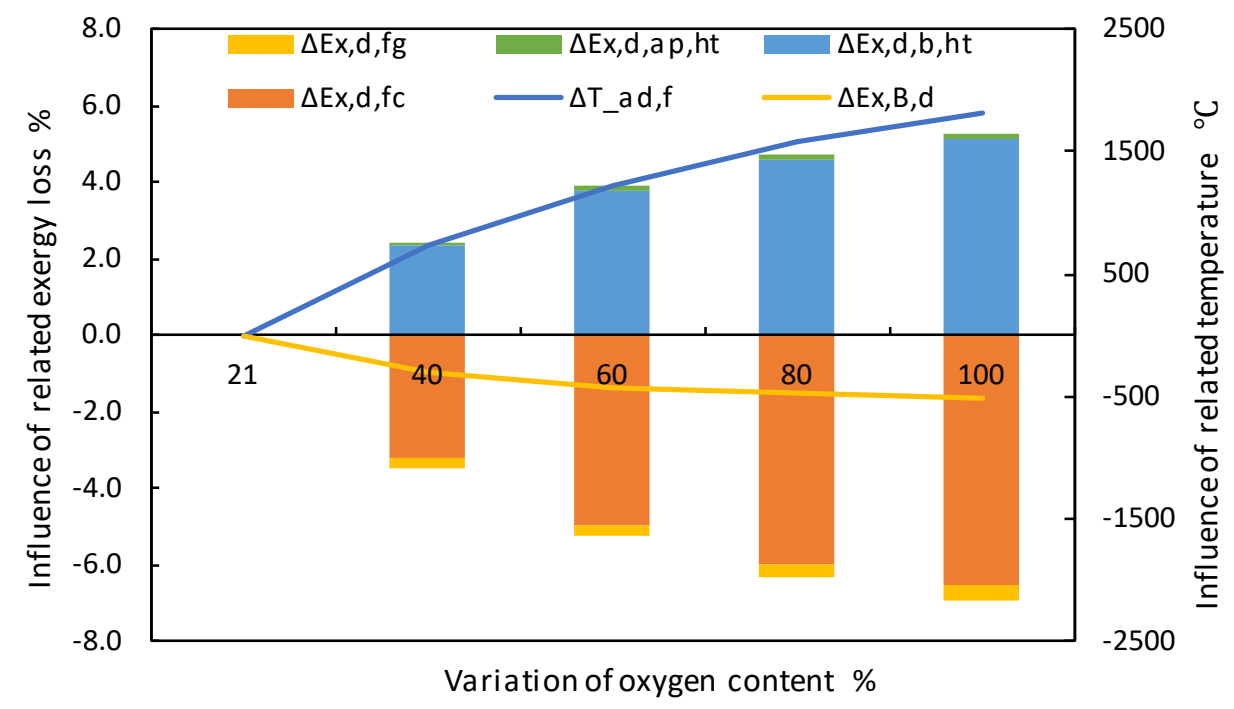

Fig. 4 Influence of oxygen content in the air

As shown in Figure 4, the adiabatic combustion temperature of the pulverized coal can be increased by about $1800{ }^{\circ} \mathrm{C}$ as the oxygen content in the air increases to $100 \%$, consequently, a significant decline in combustion-induced exergy destruction is achieved. Meanwhile, as the adiabatic combustion temperature increase, the heat transfer temperature difference between the flue gas and the water/steam increases correspondently, which leads to a increment of the heat-transfer-induced exergy destruction. As shown by the figure, the heat-transfer-induced exergy destruction grows obviously as the increment of oxygen content. Besides, the increment of adiabatic combustion temperature also increases the average temperature difference between the flue gas and the air in air preheater slightlym thus, it is seen that the exergy destruction induced by air preheater heat transfer slightly increases as the increment of oxygen content. As discussed previously, the increment of oxygen content will reduce the overall heat capacity of flue gas, hence, the exergy destruction induced by the flue gas exhaust declines, which is seen in figure 4 with a descent amplitude of around twice of the increased amplitude of the exergy destruction induced by air preheater heat transfer.

Overall adiabatic combustion temperature and the exergy destruction induced by combustion and heat transfer will experience a changing speed from a relatively fast one to a gradually gentle one as the oxygen content in the air increases. Consequently, the total exergy destruction of the boiler initially declines and then gradually tends to be even. When the oxygen content in the air increases from $21 \%$ to $40 \%$, the total exergy destruction of the boiler declines by about $1 \%$, reducing the net coal-consumption rate of over $6 \mathrm{~g} / \mathrm{kW} \cdot \mathrm{h}$. When the oxygen content in the air further increases to $100 \%$, the total exergy destruction of the boiler declines by another $0.6 \%$, resulting in a further net coal-consumption rate of $\sim 4 \mathrm{~g} / \mathrm{kW} \cdot \mathrm{h}$.

\section{(3) Reduction of excess air coefficient}

During the combustion of pulverized coal, the air exerts a certain resistance against oxygen diffusion towards the 
fuel surface. An additional air supply is needed to improve the combustion efficiency. Excess air coefficient is the ratio of actual air amount to the theoretical air amount, which is generally about 1.2 for a large coal-fired boiler. In consideration of the differences in combustion mode and pulverized coal quality, the studied range of excess air coefficient is set at 1-1.3. Ignoring the change in combustion efficiency, the effect of reducing excess air coefficient on the related exergy destruction and key temperatures were calculated and shown in Figure 5.

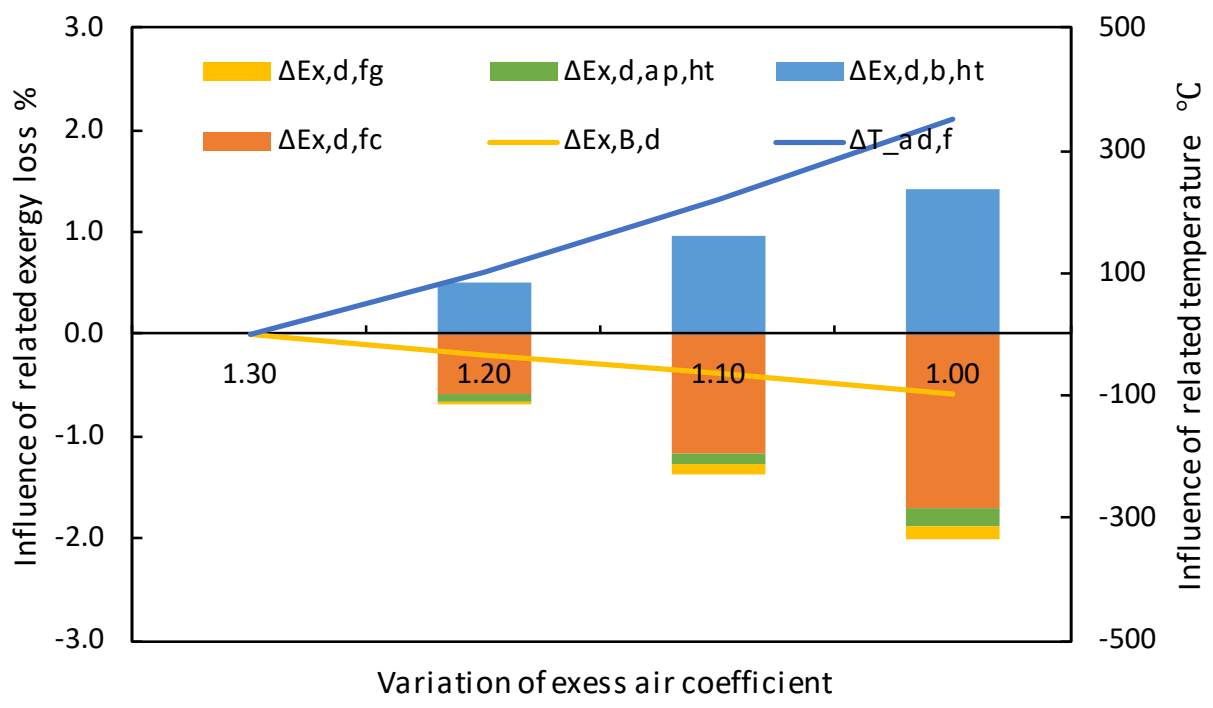

Fig. 5 Influence of excess air coefficient

By assuming that the combustion efficiency is not affected by reducing the excess air coefficient (the influence in real case is supposed to be compensated by other method), as the excess air coefficient declines, the overall flue gas heat capacity is reduced, the adiabatic combustion temperature would be increased (a power function with a power of -1). It can be seen in Figure 5 that, as the excess air coefficient declines gradually from 1.3 to 1 , the adiabatic combustion temperature is gradually elevated with an accelerated rate. Along with the adiabatic combustion temperature increases, as discussed previously, the combustion-induced exergy destruction declines, the exergy destructions induced by boiler heat transfer and air preheater increase, which are also seen in Figure 5.Besides, as the reduction of excess air coefficient leads to the overall flue gas heat capacity, the exergy destruction induced by flue gas exhaust would be reduced giving the same flue gas exhaust temperature. As a cumulative effect, the total exergy destruction of the boiler has a nearly linear decline. As the excess air coefficient declines by 0.1 , the total exergy destruction of the boiler is reduced by about $0.2 \%$, reducing the net coal-consumption rate at about $1.3 \mathrm{~g} / \mathrm{kW} \cdot \mathrm{h}$.

\subsubsection{Approaches in reducing the exergy destruction induced by heat transfer}

Table 3 shows an exergy destruction induced by heat transfer at about $16.5 \%-20 \%$ with a monotonic decline trend as the main steam parameter increases. It is caused by the heat transfer temperature difference between the flue gas and steam/water. Given a specific combustion mode, the reduction of exergy destruction induced by heat transfer can be solely realized by elevating the average heat absorption temperature at the steam/water side, which can be achieved by elevating main steam/reheated steam pressure/temperature, elevating feedwater temperature, and optimizing parameters of cold reheated steam. The feedwater temperature should consider the investment on the regenerative system and subcooling of the water in economizer, which would limit the improvement margin. The selection of cold reheated steam parameters is always optimized in the turbine design, which is not included in this paper. Therefore, the emphasis of this part will be laid on discussing the influences of the main steam pressure, main steam temperature, and reheated steam temperature on the exergy destruction induced by heat transfer and the corresponding net coal-consumption rate of the unit.

The temperature of reheated steam is generally designed to be identical with or close to that of the main steam. Hence, the reheated steam temperature is synchronously considered in this paper without separate discussion. The 
changes in the temperature and pressure of the main and reheated steam barely affects the exergy destructions in the boiler system other than the exergy destruction induced by boiler heat transfer. Figure 6 shows the variations of the exergy destruction induced by boiler heat transfer when the main/reheated steam temperature increases gradually from $540{ }^{\circ} \mathrm{C}$ to $800{ }^{\circ} \mathrm{C}$ under different main steam pressures. According to Fig. 6 , the exergy destruction induced by heat transfer has a nearly decline as the main/reheated steam temperature increases. Each $100{ }^{\circ} \mathrm{C}$ increment in the main/reheated steam temperature would result in a $\sim 1.8 \%$ reduction in the exergy destruction induced by heat transfer, contributing to a reduction of the net coal-consumption rate of the unit by $\sim 11 \mathrm{~g} / \mathrm{kW} \cdot \mathrm{h}$.

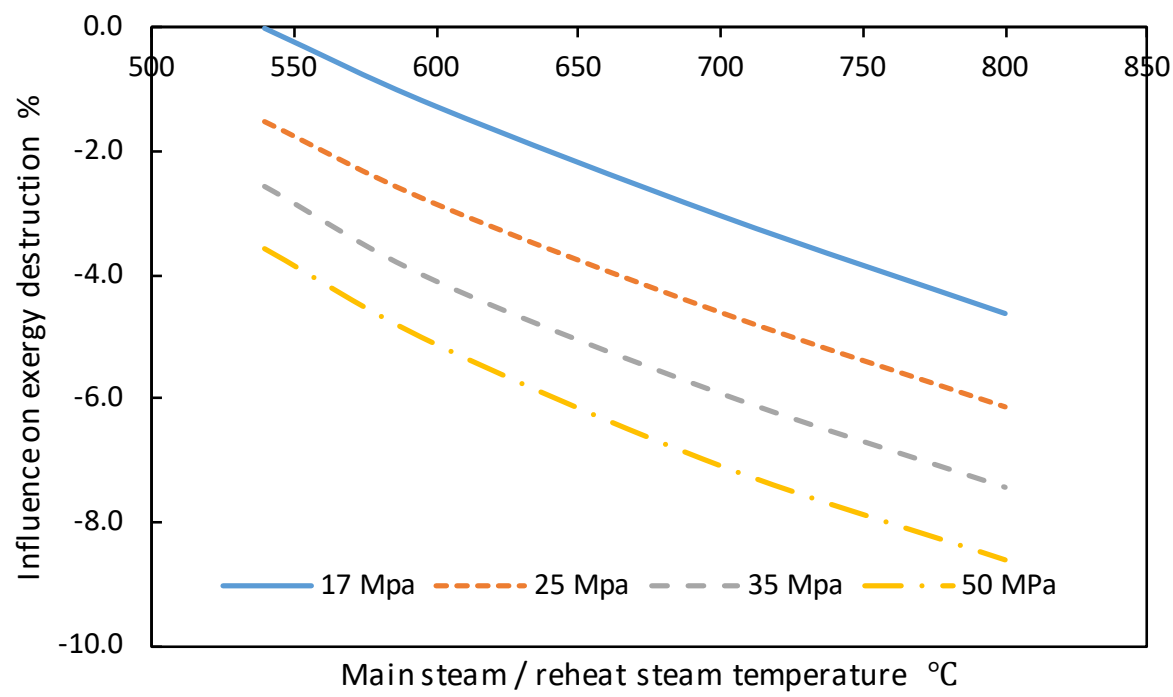

Fig. 6 Influence of main steam temperature/pressure on the exergy destruction induced by heat transfer

Figure 6 also shows that the exergy destruction induced by heat transfer declines monotonously as the main steam temperature increases, but the descending trend becomes gradually mild. A $10 \mathrm{MPa}$ increment in the main steam pressure within 17-27 MPa may lead to a decline of 2\% in the exergy destruction induced by heat transfer, reducing the net coal-consumption rate by $\sim 12 \mathrm{~g} / \mathrm{kW} \cdot \mathrm{h}$. A $10 \mathrm{MPa}$ increment in the main steam pressure within 35-50 MPa decreases the exergy destruction induced by heat transfer only by $0.7 \%$, reducing the net coal-consumption rate by $\sim 5 \mathrm{~g} / \mathrm{kW} \cdot \mathrm{h}$.

\section{Conclusion}

A comparative investigation between the approaches of thermal and exergy equilibria was carried out on four typical coal-fired power generation units to evaluate the energy conversion and transfer process. Then, the energy-destruction mechanism of coal-fired power generation was revealed. The exergy destruction characterized the concrete energy loss process, whereas the heat loss indicates the accumulated energy loss quantity as well as the discharge ports in the coalfired power generation process. The exergy-destruction distribution represents the theoretical energy-saving potentials, whereas the specific values should depend on the current related technologies and the specific approaches. The energysaving potential in the coal-fired power generation process mainly occurs in the boiler.

According to the exergy-destruction distribution of a typical $1000 \mathrm{MW}$ ultra-supercritical unit, a comprehensive study was conducted on the effects of technical approaches (staged air preheating to elevate the hot-air temperature, oxy combustion, reduction of excess air coefficient, and elevation of the main/reheated steam parameters) on the reduction of exergy destruction induced by combustion, heat transfer, and others. By elevating the hot-air temperature by $40-60{ }^{\circ} \mathrm{C}$, increasing the oxygen content in the air to over $40 \%$, elevating the temperature of the main and reheated steam by $100{ }^{\circ} \mathrm{C}$, and elevating the pressure of the main steam by $10 \mathrm{MPa}$, the net coal-consumption rate of the selected $1000 \mathrm{MW}$ power unit can be reduced by $6-9,6-10,11$, and $5-12 \mathrm{~g} / \mathrm{kW} \cdot \mathrm{h}$, respectively. These approaches set important directions for the development of energy-saving technologies in the coal-fired power generation industry.

\section{Acknowledgement}


This work was supported by the National Key Research and Development Program of China (2016YFB0600205), the State Key Laboratory of clean and efficient coal-fired power generation and pollution control (D2018Y001-12), and China Postdoctoral Science Foundation (2017M620758).

\section{References}

Adibhatla, S., Kaushik, S. C., Energy, exergy and economic (3E) analysis of integrated solar direct steam generation combined cycle power plant, Sustainable Energy Technologies and Assessments, Vol.20 (2017) pp.88-97.

BP Company, Energy demand by fuel, available from <https://www.bp.com/en/global/corporate/energyeconomics/energy-outlook/demand-by-fuel.html>, (accessed in 2018).

Chen, L., Applied Program of Boiler in Power Plant on Thermodynamic Calculation and Exergy Analysis[D]. (2004).(In Chinese)

China Electricity Council, Annual development report of China's power industry (2018)[R], Beijing: (2018).

Compton, M., Rezaie, B., Enviro-exergy sustainability analysis of boiler evolution in district energy system, Energy, Vol.119 (2017) pp.257-265.

Darvish, K., Ehyaei, M., Atabi, F., Rosen, M., Selection of Optimum Working Fluid for Organic Rankine Cycles by Exergy and Exergy-Economic Analyses, Sustainability, Vol.7, No.11 (2015) pp.15362-15383.

Feng, J., Shen, Y., Yang, R., Boiler Theory and Calculation[M]. Beijing: Science Press (2003).(In Chinese)

Feng, J., Yue, G., Lv, J., Circulating Fluidized Bed Combustion Boiler[M]. Beijing: Electric Power Industry Press (2003).(In Chinese)

Gürtürk, M., Oztop, H. F., Exergy analysis of a circulating fluidized bed boiler cogeneration power plant, Energy Conversion and Management, Vol.120 (2016) pp.346-357.

Han, X., Liu, M., Yan, J., Zhong, D., Liu, J., Xiao, F., Exergy Analysis and System Optimization of a Flue Gas Pre-dried Lignite-fired Power System Based on Fan Mill Dryer and Open Pulverizing System, No.02 (2017) pp.148-155.(In Chinese)

Iea, Electricity Statistics, available from <http://www.iea.org/statistics/electricity/>, (accessed in 2018).

Jin, B., Zhao, H., Zheng, C., Dynamic exergy method and its application for CO2 compression and purification unit in oxy-combustion power plants, Chemical Engineering Science, Vol.144 (2016) pp.336-345.

Li, J., Energy Balance Calculations for a Power Plant Boiler, Journal of Xi'an Jiaotoong University, Vol.20, No.02 (1986) pp.87-97.(In Chinese)

Li, Y., Xu, G., Xue, X., Zheng, Q., Xu, C., Yang, Y., Performance Analysis of the Efficient Integrated System of Coalfired Power Plant Based on

Optimized Primary Air Heating Process, Proceedings of the CSEE, Vol.37, No.20 (2017) pp.5970-5979.(In Chinese)

Liu, Q., Duan, Y., Exergy Analysis for Thermal Power System of a 600MW Supercritical Power Unit, Proceedings of the CSEE, Vol.30, No.32 (2010) pp.8-12.(In Chinese)

Menberg, K., Heo, Y., Choi, W., Ooka, R., Choudhary, R., Shukuya, M., Exergy analysis of a hybrid ground-source heat pump system, Applied Energy, Vol.204 (2017) pp.31-46.

Nami, H., Akrami, E., Analysis of a gas turbine based hybrid system by utilizing energy, exergy and exergoeconomic methodologies for steam, power and hydrogen production, Energy Conversion and Management, Vol.143 (2017) pp.326-337.

National Bureau of Statistics of China, China statistical yearbook 2016[M]. Beijing: China statistics press (2017).(In Chinese)

Semkov, K., Mooney, E., Connolly, M., Adley, C., Efficiency improvement through waste heat reduction, Applied Thermal Engineering, Vol.70, No.1 (2014) pp.716-722.

Sengupta, S., Datta, A., Duttagupta, S., Exergy analysis of a coal-based $210 \mathrm{MW}$ thermal power plant, International Journal of Energy Research, Vol.31, No.1 (2007) pp.14-28.

Si, N., Zhao, Z., Su, S., Han, P., Sun, Z., Xu, J., Cui, X., Hu, S., Wang, Y., Jiang, L., Zhou, Y., Chen, G., Xiang, J., Exergy analysis of a $1000 \mathrm{MW}$ double reheat ultra-supercritical power plant, Energy Conversion and Management, Vol.147 (2017) pp.155-165. 
Thomson, W., On an Absolute Thermometric Scale founded on Carnot's Theory of the Motive Power of Heat and calculated from Regnault's Observations, Revista Brasileira de Ensino de Física, Vol.29, No.4 (1848) pp.487-490.

Tillman, D. A. 2018. Chapter Eight - Coal-Fired Power Plants: 2000 - Present and Beyond[M]//Tillman D A.Coal-Fired Electricity and Emissions Control. Butterworth-Heinemann: 207-236.

Tumen Ozdil, N. F., Tantekin, A., Erbay, Z., Energy and exergy analyses of a fluidized bed coal combustor steam plant in textile industry, Fuel, Vol.183 (2016) pp.441-448.

Uysal, C., Kurt, H., Kwak, H., Exergetic and thermoeconomic analyses of a coal-fired power plant, International Journal of Thermal Sciences, Vol.117 (2017) pp.106-120.

Wang, W. A staged air preheater boiler[P]. 2016.03.30, 2015210466421. 2016.03.30[2016.03.30].

Wang, Y., Xia, J., He, H., He, H., Efficiency Analysis of Boiler of 600MW Supercritical Thermal Power Generator Set, Industrial Heating, Vol.45, No.01 (2016) pp.5-8.(In Chinese)

Xiang, X., The Concept of Exergy and its Evaluation, Oilfield surface engineering, Vol.4, No.01 (1985a) pp.27-35.(In Chinese)

Xiang, X., Combustion on Chemical Exergy, Oilfield surface engineering, Vol.4, No.06 (1985b) pp.31-37.(In Chinese)

Yang, Y., Wang, L., Dong, C., Xu, G., Morosuk, T., Tsatsaronis, G., Comprehensive exergy-based evaluation and parametric study of a coal-fired ultra-supercritical power plant, Applied Energy, Vol.112 (2013) pp.1087-1099.

Zhao, C., Zheng, S., Zhang, J., Zhang, Y., Exergy and economic analysis of organic Rankine cycle hybrid system utilizing biogas and solar energy in rural area of China, International Journal of Green Energy, Vol.14, No.14 (2017) pp.12211229.

Zhu, M., A Rational Utilization Method of Exergy and Energy, Energy, No.01 (1983) pp.32-35.(In Chinese)

Zhu, Y., Zhai, R., Peng, H., Yang, Y., Exergy destruction analysis of solar tower aided coal-fired power generation system using exergy and advanced exergetic methods, Applied Thermal Engineering, Vol.108 (2016) pp.339-346. 